\title{
Effectiveness of an Alternative Digital Learning Environmentfor Steel Connection Design Education
}

\author{
Borinara Park
}

\begin{abstract}
The VR is an exact copy of a real learning environment that operates in a 3-D cyber space, which is accessible through the internet connections. This paper describes a project aiming at creating and operating an innovative virtual reality (VR) learning environment to seek answers for the following questions: 1) Are there differences in students' understanding of construction engineering concepts when taught in a 3D graphical VR simulation environment vs. a traditional classroom environment?; and 2) How do the perceptions of construction students exposed to a 3D graphical VR simulation differ from those students enrolled in a traditional classroom setting? This study utilizes a quasi-experimental research design. Target subjects are enrolled in two sections of the Construction Management computer application course. The experimental or treatment group is comprised of 24 students who participate in a 3D graphical VR class on the steel structural design concept. The control group is also comprised of 25 students who participate in a regular class. The VR learning environment isa 3D graphical replica of a real steel structure. It provides highly visual, immersive, interactive, and sociable learning space.The study shows that the performance of the students in the virtual environment is almost at the same level as the students who learn in a real-life based setting. The students, however,do not perceive the virtual learning environment as effective as the real-life based learning environment although they agree that the new technology havemerits to improve their learning.
\end{abstract}

Index Terms-Steel connection design, hybrid course delivery, alternative learning environment, virtual reality

\section{INTRODUCTION}

A Virtual Reality (VR) learning environment is a cyber campus where teaching and learning could occur. A VR cyber classroom is an exact copy of the real learning environment, which operates in a 3-D graphical space (see Fig. 1). This environment includes almost everything that appears in the educational settings, i.e., building, people, technology, talking, discussion, question and answer, lab activity, and emotional expression. It provides learners with richer, more interactive, and more accessible education environments. Individual VR participants sign in as avatars using over the internet, fly into the cyber learning space, and become independent identities interacting with other avatar learners. Since this virtual learning environment is accessible via the internet, students can interact in real-time with other avatars such as experts and learning partners from remote places to share information and thoughts. Therefore, this VR

Manuscript received April 20, 2012; revised June 8, 2012.

This work was supported in part by the Illinois State University's 08-09 URG program.

B. Park is with Illinois State University, Normal, IL 61790 USA (e-mail: bpark@ilstu.edu). learning environment intends to provide internet-based 3D synchronous/ asynchronous interactive learning experiences.

Innovative educators have explored and experimented with the virtual reality (VR) simulation technology [1]. For example, New Media Consortium has created an immersive 3-D virtual learning environment, as shown in Fig. 1, for higher education to explore the boundaries of what is possible in education [2]. Case studies of this technology and its associated benefits have been reported in various areas such as aerospace, architecture, computer science, and earth sciences [3]-[6].

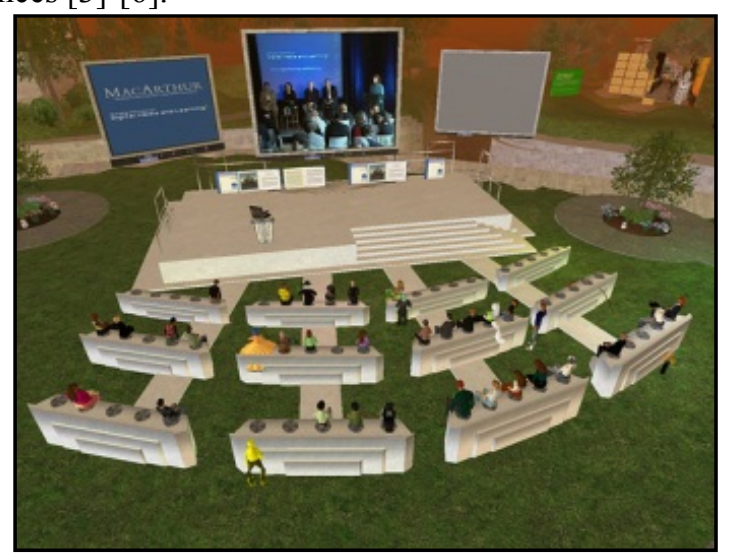

Fig. 1. Avatar learners in virtual learning environment

\section{LEARNING ENVIRONMENTS}

As an attempt to test this new technology as a potential tool for construction management (CM) education, in this paper, a small-scale prototype of a CM virtual lab was developed as an alternative learning environment [7]-[8]. The CM virtual lab runs on the Second Life (SL) platform, which is an internet-based highly graphical 3D virtual space where the contents are created by the individual users [9]. For most users, this is no different than surfing the website except SL is highly visual and more realistic. The main purpose of the Second Life CM learning environment is to provide a highly visual, immersive, interactive, and sociable internet-based learning space for students and faculty to explore various teaching/ learning opportunities in CM education.

\section{A. Conventional Learning Environment}

The steel structure/ connection design is used as a topical subject to conduct the comparison of learning experience and performance between in real life learning environment and in the alternative virtual learning environment. In conventional learning, students are typically provided with the idealized structures in the steel connection design documents where beams, columns, connections, and other structural components are represented in a $2 \mathrm{D}$ graphical format [10]. To improve student learning, some institutions provide the real 
steel design and connections through the steel sculpture. Fig. 2 shows these conventional teaching/ learning resources for the steel structure and connection design.

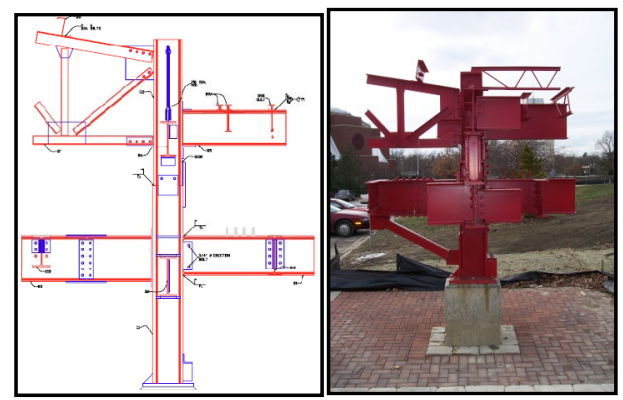

Fig. 2. Conventional steel structurelearning resources: $2 \mathrm{D}$ vs. actualrepresentations

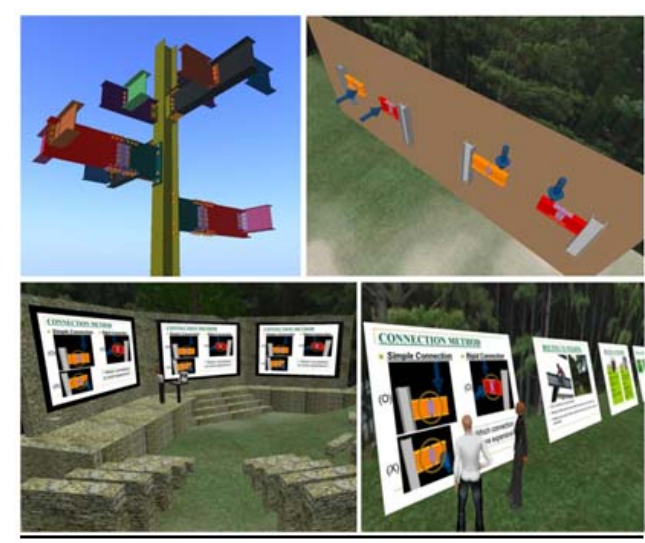

Fig. 3. Virtual CM lab/ virtual learning (VL) environment

\section{B. Alternative Virtual Learning Environment}

For this study, the virtual CM lab, as a virtual learning (VL)environment, was developed as a replica of the steel sculpture to allow students to virtually explore different parts of a steel structure and learn engineering concepts related to the structural steel connection design. In this learning environment, each student using his/ her own avatar immerses into the 3D virtual classroom, and learns a steel structure design by listening to lectures, communicating with their colleagues, and interacting with the 3D graphical steel structure. Fig. 3 shows the screen shot of this virtual CM lab/ virtual learning (VL) environment, which is comprised of various teaching/ learning tools to provide highly interactive and realistic learning experience for students and teachers. Specifically, thevirtualsteel structure replica (shown in the upper left of Fig. 3) has all the same structure/ connection design components as its physical counterpart such as moment connections and shear connections coupled with several splices. It was created intentionally bigger ( 50 feet tall) than the real structure to allow easier exploration and interactions for students. The Shear/ moment exhibition board (shown in the upper right of Fig. 3) was developed to provide easier visualization and explanation of major external forces to the steel structure and to promote students' understanding how various connections handle different loading conditions. To provide the teaching opportunity for lecture and presentation, the outdoor space (shown in the lower left of Fig. 3) was set up with the multi-purpose screens, instructor stations, and seats for the audience or students. It was designed to accommodate any typical class size up to
100 students. The screen was designed to handle any multimedia files such as videos, movies, and even presentation slides such as Powerpoint files. To serve a group of students who might prefer more active learning than sitting to listen to lecture or who might not be present at the lecture, the stand-up presentation board was implemented as a secondary learning resource (shown in the lower right of Fig. 3).

\section{ReSEARCH Methodology}

\section{A. Research Questions}

In this VR learning environment, each student using his/ her own avatar (digital self in VR, see Fig. 1 and Fig. 3 for student avatars) immerses into the $3 \mathrm{D}$ virtual classroom, and learns a steel structure design concepts by interacting with the 3D graphical steel structure parts by which the experiment is carried out.

This project adopts these features for engineering education to seek two factors in student learning: 1) their conceptual understanding of a steel design concept; and 2) their perception on this new innovative learning environment. The following questions will guide this study:

1) Are there differences in students' understanding of steel connection design theory and application when taught in a 3D graphical VR simulation environment vs. a traditional classroom environment?

2) How do the perceptions of construction students exposed to a 3D graphical VR simulation differ from those students enrolled in a traditional classroom learning environment?

\section{B. Sample and Procedures}

TABLE I: RESEARCH PROCEDURE

\begin{tabular}{|c|c|c|c|}
\hline & Control Group & & Experiment Group \\
\hline & & \begin{tabular}{|l|} 
Practice \\
Session 1 \\
\end{tabular} & $\begin{array}{l}\text { 1st Virtual Learning (VL) } \\
\text { Training }\end{array}$ \\
\hline & & \begin{tabular}{|l|} 
Practice \\
Session 2 \\
\end{tabular} & $\begin{array}{l}\text { 2nd Virtual Learning } \\
\text { (VL)Training }\end{array}$ \\
\hline 1st Class & Real Life (RL) Lecture & 1st Class & VL Lecture \\
\hline \multirow{4}{*}{ 2nd Class } & Jecture Reviews & \multirow{4}{*}{ 2nd Class } & Jecture Reviaw \\
\hline & RL Connection Exercise & & VL Connection Exercise \\
\hline & RL Field Observation & & VL Field Observation \\
\hline & RL Exercise Review & & VL Exercise Review \\
\hline \multirow{2}{*}{ 3rd Class } & Performance Assessment & \multirow{2}{*}{$3 r$ Class } & Performance Assessment \\
\hline & RL Environmental Survey & & VL Environmental Survey \\
\hline
\end{tabular}

This study utilized a quasi-experimental research design wherethe target subjects enrolled in a Construction Management computer application course, which were offered in two different sections. The control group was comprised of 25 students from the $1^{\text {st }}$ section of the course who would participate in a regular conventional class for learning the concepts related to steel structural connection design. The experimental or treatment group was comprised of 24 students from the $2^{\text {nd }}$ section who would participate in a 3D graphical VR class for learning the same topics.The details of the research procedures are described in TABLE I.

The students in the control group took the lecture on the steel connection and frame concepts in a conventional class room setting. The topics discussed included external/ internal 
forces applied in a steel structure, simple/ rigid connection methods, and braced/ rigid frames. The instructor used the typical in-class resources and tools such as presentation slides, handouts, and projection devices to transfer the information to the students. In the $2^{\text {nd }}$ class meeting after the lecture, the students were provided with the steel connection design exercise questions as a way of reviewing the lecture materials they learned previously. As a way of reviewing the exercise questions, students were given a short field observation opportunity by visiting the physical steel model available just outside the class room building. Fig. 4 shows this active learning resource the students used to enhance their learning of the steel designs. The steel sculpture demonstrated various steel connections types, which could be easily explored by students.

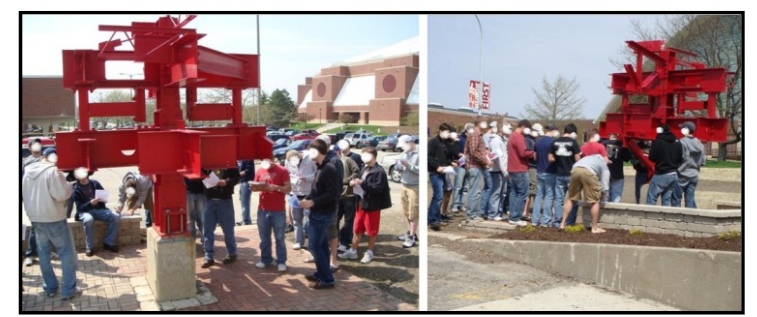

Fig. 4. Study of steel structure/ connection design using a real steel sculpture
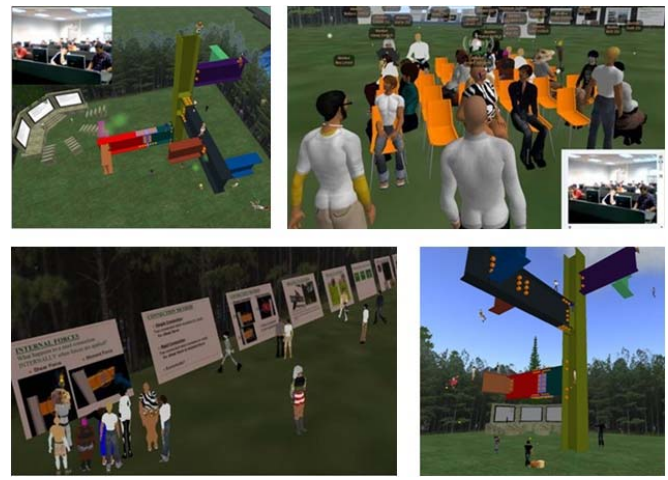

Fig. 5. Study of steel structure/ connection design inthe virtual learning (VL) environment

For the students in the experiment group, all the same steel design topics were handled in the virtual CM lab as shown in Fig. 5. Students had their presence in the virtual learning (VL) environment through the digital avatars. Since this was the first time experience for most students, a couple of training sessions were held so that they could get used to the new learning environment. The student learned how to navigate the environment, exchange information with other virtual participants, and use virtual learning tools and resources to participate in the class activities. For the $1^{\text {st }}$ class, the instructor delivered the lecture virtually in the virtual CM lab. Even though the instructor was not in the same room physically with the students, they were all in the same virtual space. The instructor talked through the microphone and the students listened via their headphone sets and asked questions using the chatting program.For the lecture, the instructor used the multi-screen outdoor display and the presentation boards. The $2^{\text {nd }}$ class was also conducted in the virtual learning environment where the class reviewed the lecture done in the previous class and the students answered the questions for the steel connection design exercise as the control group students did. The virtual steel sculpture was used for students to reinforce their understanding by navigating through various steel connection methods. To do this, they had to fly around the structure and took their time to investigate specific connection points.

\section{Data Collection and Analysis}

Once all the learning activities occurred in the real and virtual learning environments, the learning outcomes were assessed for both control and experiment group students.

For research question \#1, the performance-based assessment of the concept of steel connection design was conducted to measure student's understanding of the technical subject matters. A t-test was used to assess differences in learning outcomes between the two groups of students.

For research question \#2, the study utilized a Learning Environment Survey to assess student perceptions about the learning environment. The survey questions are as follows:

- Did the learning environment provide the steel connection design visually for better understanding of the concept?

- Did the learning environment encourage students to explore the steel connection design easily?

- Did the learning environment allow efficient communication betweern students?

- Did the learning environment allow efficient communication betweern students and the instructor?

- Was the learning environment sensitive to students' lerning style, needs, and preferences?

- Did the learning environmentprovide good learning tools/ environment?

A level how much students agreed with each question was asked and it was converted to a numerical value ("Strongly Aree" is given 5 points, "Moderately Agree" 4, "Neither Agree or Disagree" 3, "Moderately Disagree" 2, and "Strongly Disagree" is given 1). The data was then analyzed using a t-test to determine if there were differences between the two groups of students for their perception on the respective learning environments.TABLE II summarizes the research data collection and analysis devices.

TABLE II: RESEARCH DATA COLLECTION AND ANALYSIS

\begin{tabular}{||l|l|l||}
\hline Research Question & Data Sources & Analysis \\
\hline $\begin{array}{l}\text { Learning } \\
\text { Differences }\end{array}$ & $\begin{array}{l}\text { - Performance- } \\
\text { Based Assessment }\end{array}$ & $\begin{array}{l}\text { t-test compare mean score } \\
\text { of treatment and control } \\
\text { groups }\end{array}$ \\
\hline $\begin{array}{l}\text { Student } \\
\text { Perceptions }\end{array}$ & $\begin{array}{l}\text { - Learning } \\
\text { Environment } \\
\text { Survey }\end{array}$ & $\begin{array}{l}\text { t-test compare mean score } \\
\text { of treatment and control } \\
\text { groups }\end{array}$ \\
\hline
\end{tabular}

\section{Mitigation of the Study-Related Concerns}

To minimize a Hawthorne effect (any novelty induced improves performance) and to prevent a cross-contamination between the groups, the VR component was introduced to both treatment and control group early on in the semester for other class activities. Therefore, when this tool was used for the main study, it would be less likely that the students from both groups perceived it as a novelty.

To make sure this study focused on difference between conventional vs. virtual deliveries (and not to be confounded with group/ individual and traditional/ online differences), all 
the students of the treatment group met in a computer lab as a group individually accessing the virtual learning environment. Therefore it eliminated the learners' psychological effect that they tookthe class from the distant isolated locations.

\section{RESEARCH OUTCOMES}

\section{A. Performance Comparison between $R L$ and $V L$}

A t-test was performed using the performance-based assessment data to analyzethe difference in the technical learning outcomes between the two groups of students. The sample mean scores of the control and experiment group students were 93 and 94, respectively, and while the sample standard deviations were 8.97 and 7.94, respectively. The t-test results indicated that there was not a significant difference (at any levels of significance) in the student technical learning outcomes between in the real life and virtual learning environments. Fig. 6 shows the distribution of the student scores and the t-test summary.This provided an answer to the 1st research question on the real vs virtual learning environment's effect on student learning of the steel connection design.
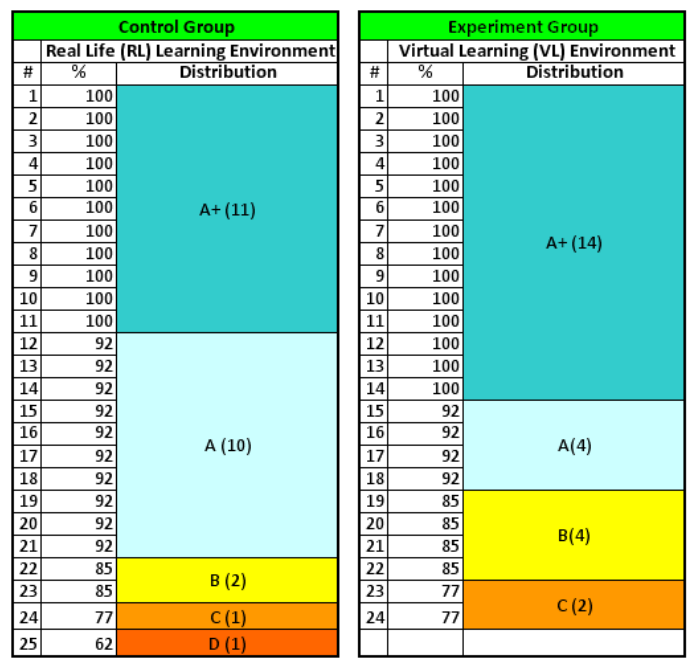

\begin{tabular}{|l|c|c|}
\hline Sample Summaries & $\%$ & $\%$ \\
\hline Sample Size & Perf. RL Data & Perf. VL Data \\
\hline Sample Mean & 25 & 24 \\
\hline Sample Std Dev & 93.231 & 94.231 \\
\hline & 8.971 & 7.939 \\
\hline Hypothesis Test (Difference of Means) & Eariances & Unequal \\
\hline Hypothesized Mean Difference & 0 & 0 \\
\hline Alternative Hypothesis & $<12$ & $<12$ \\
\hline Sample Mean Difference & -1.000 & -1.000 \\
\hline Standard Error of Difference & 2.423819369 & 2.417687021 \\
\hline Degrees of Freedom & 47 & 46 \\
\hline t-Test Statistic & -0.4126 & -0.4136 \\
\hline p-Value & 0.6818 & 0.6811 \\
\hline Mull Hypoth. at 10\% Significance & Don't Reject & Don't Reject \\
\hline Mull Hypoth. at 5\% Significance & Don't Reject & Don't Reject \\
\hline Hull Hypoth. at 1\% Significance & Don't Reject & Don't Reject \\
\hline
\end{tabular}

Fig. 6. Performance outcomes between the two learning environments

\section{B. Perception Survey Results}

Both the control and experiment group students provided their feedback on the $2^{\text {nd }}$ research question that how they perceived their respective learning environment. The results are summarized in Fig. 7 where the control group students showed moderately strong agreement that the real learning environment was conducive to promoting their learning and meeting their learning needs (aggregate agreement average was 4.5 , between 5 being the strong agreement and 4 being the moderate agreement). On the other hand, the experiment group rated their virtual learning experience as somewhat positive (aggregate agreement average was 3.4, between 4 being the moderate agreement and 3 being neutral). Statistically, based on the t-test, in almost all the questions (except question Q2), the virtual learning environment was perceived to be not more effective than the real life learning environment. In particular, when compared with the control group students, the experiment group students displayed a relatively weaker satisfaction level with the communication aspect in the virtual learning environment. However, they rated the virtual learning environment favorably in the visual and exploration-encouraging elements of the virtual environment.

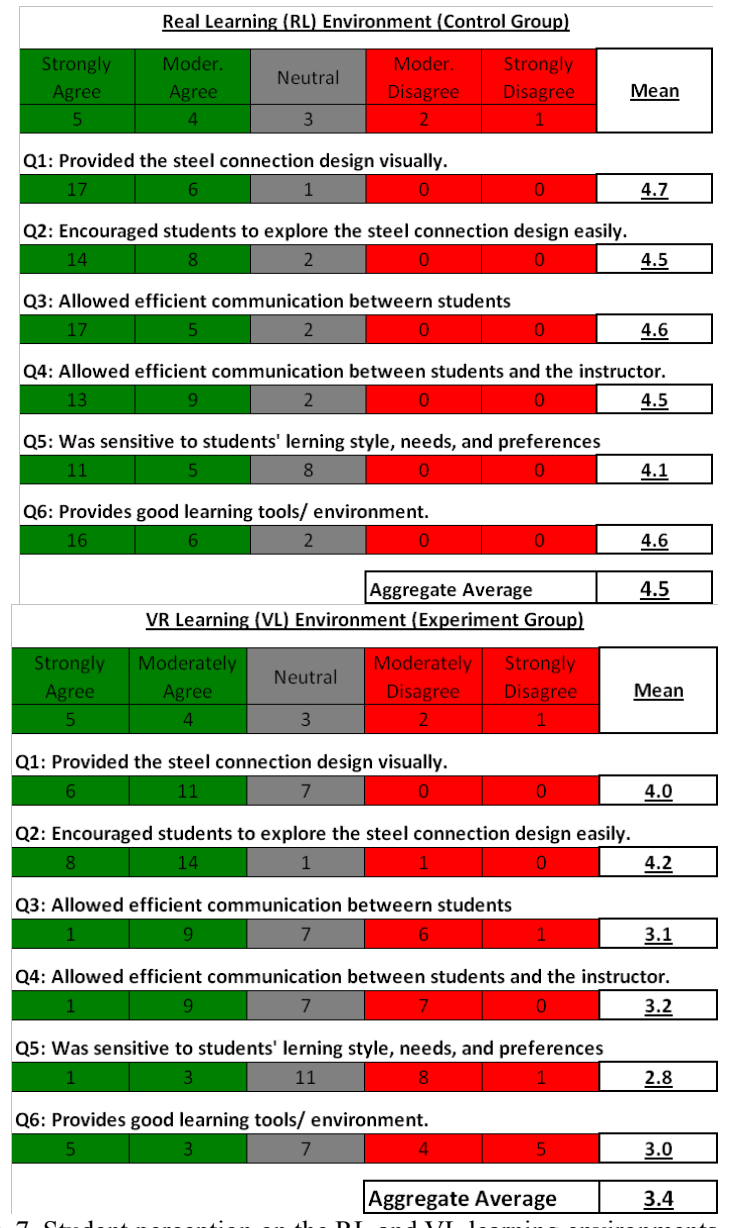

Fig. 7. Student perception on the RL and VL learning environments

\section{CONCLUSION}

The 3D internet-based virtual space such as the Second Life platform provides promising qualities and resources to be an alternative environment for education. This alternative delivery technology has been known to provide major advantages such as its visual realism, unrestricted creation of learning materials and resources, and various ways of interaction/ communication tools [7]-[8].

In this paper, the effectiveness of the virtual learning environment was tested by applying it in the technical education of the steel structure connection in a construction curriculum at a university setting. The performance of the 
students who were engaged in the learning activities in the virtual environment was almost at the same level as the students who learned in a real-life based setting. This testified the potential of this new environment either as a potential environment replacing the real-life based but expensive learning settings or complementing the traditional textbook-based passive learning.

The students did not perceive the virtual learning environment as effective as the real-life based learning environment even though they agreed on the fact that the new technology had some merits such as its reality-defying and unlimited resourcefulness.

As much as the study revealed the potential of this new alternative approach, it also helped us realize that learning takes place in fact very much part of the system the students have been used to. Unless they feel comfortable and confident with the new technology, regardless of its technical capability, the students would not be able to maximize the benefits. For this reason, the author recommends using this technology gradually so that students and instructors alike can develop their appreciation and skill sets.

\section{ACKNOWLEDGMENT}

The author thanks Illinois State University for its financial support through the 08-09 University Research Grant program and students who were eager to explore the new learning environment and provide feedback for its improvement.

\section{REFERENCES}

[1] Sim Teach, Second Life Education Wiki, [Online]. Available: http://www.simteach.com/wiki/index.php?title=Second_Life_Educati on Wiki, accessed in 2007

[2] New_Media_Consortium. New Media Consortium. [Online]. Available: http://www.nmc.org/sl, accessed in 2007

[3] K. Cochrane, Case Study: International Spaceflight Museum," presented at the Proceedings of the Second Life Education Workshop, San Francisco, CA, 2006
[4] P. Doherty and R. othfarb, "Building an Interactive Science Museum in Second Life," presented at the Proceedings of the Second Life Education Workshop, San Francisco, CA, 2006

[5] E. Hackathorn, "Designing an Educational Island inside Second Life for the National Oceanic and Atmospheric Administration (NOAA) Earth System Research Laboratory (ESRL)," presented at the Proceedings of the Second Life Education Workshop, San Francisco, CA, 2006

[6] C. Lagorio, "Ultimate Distance Learning," The New York Times, January (online version), 2007

[7] B. Park, "CM Education in Second Life (SL): Virtual Lab Development, Implementation, Lessons Learned, and its Implications," 2008 Associated Schools of Construction Great Lakes Region Conference, October, 2008

[8] B. Park, "Teaching Structural Steel Connections via a 3D Virtual Learning Environment," 2008 Conference of the National Association of Industrial Technology, November $18 \sim 22,2008$, Nashville, TN

[9] Linden Lab, Second Life Website. [Online]. Available: http://secondlife.com/ (accessed 2007).

[10] AISC,Connections Teaching Toolkit: A Teaching Guide for Structural Steel Connections, American Institute of Steel Connection, Year Unknown

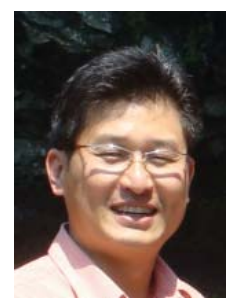

Borinara Park is an Associate Professor in Construction Management at Illinois State University. Using his multidisciplinary backgrounds in Civil Engineering, Computer Science, and Construction Management, Dr. Park has developed his teaching and research agenda in the application of the 3D graphical visualization in construction to increase the productivity of the construction professionals and to enhance the teaching practices in education. He researched on the virtual reality simulator development and developed 3D graphical machine simulators such as SimCrane and VR Excavation Simulator to optimize the field machine operations. He also expanded the capability of the 3D visualization technology by adding additional dimensional information in the VR environment from the constructor's perspective. BIM-based project management techniques have been an integral part of his project management courses that he has taught for the last 12 years. He helped professionals and students use these tools to apply their critical thinking and creativity to the problems they face. Dr. Park received his Ph. D. degree in Environmental Design and Planning at Virginia Polytechnic Institute and State University, a ME. in Geotechnical Engineering, and a BE in Civil Engineering from Korea University, in Seoul, Korea. 